\title{
Aging of thymus gland and immune system
}

\begin{abstract}
Aging is an inevitable, progressive and irreversible process that is manifested with multiple organ dysfunction. Reactive oxygen species (ROS) is considered the main etiological factor of aging. The thymus gland is the primary site of T cell production and it represents a key organ of the immune system. It is endodermal in origin and lies in the anterior mediastinum behind the sternum. Thymic involution with aging results in less efficient T-cell development and decreased emigration of naïve T cells to the periphery. Deterioration of the immune system with aging contributes to increased incidence of infection, autoimmunity, and cancer, thus increasing the rates of morbidity and mortality in elderly humans.
\end{abstract}

Keywords: aging, thymus, immune system
Volume 5 Issue 3 - 2018

\author{
Heshmat SW Haroun \\ Department of Anatomy and Embryology, Cairo University, \\ Egypt \\ Correspondence: Heshmat SW Haroun, Professor of \\ Anatomy and Embryology, Kasr Alainy Faculty of Medicine, \\ Cairo University, Egypt, Email heshmatsabet@gmail.com, \\ heshmat.haroun@kasralainy.edu.eg.com, \\ heshmat.haroun@scholar.cu.edu.eg
}

Received: March 29, 2018 | Published: May 102018
Abbreviations: CMV, cytomegalovirus; EOMG, early-onset MG; ETCE, embryonic thymic calf extracts; LHRH-A, luteinizing hormone-releasing hormone agonist; LLLT, low-level laser therapy; LOMG, late-onset MG; miRNAs, MicroRNAs; MG, myasthenia gravis; PBM, photobiomodulation; PCNA, proliferation cell nuclear antigen; PLP, postnatal low-protein; RA, rheumatoid arthritis; ROS, reactive oxygen species; SAT, subcutaneous adipose tissue; SSc, systemic sclerosis; TAT, thymus adipose tissue; TRH, thyrotropinreleasing hormone

\section{Introduction}

Aging is a multifactorial physiological condition that includes a progressive decline of organ function. It is accompanied with increased vulnerability to infections, immune disorders and neoplasms, and ultimately death. Imbalance between oxidants like free oxygen radicles (reactive oxygen species, ROS) and antioxidants is considered as an important etiology of aging. Inside the mitochondria, oxidative stress liberates excessive ROS that induces more mitochondrial damage and more ROS, and the cycle repeats itself. ${ }^{1,2}$ Inside the cells, mitochondria are the major factory for ROS formation. ${ }^{3}$ It is hypothesized that none of the individual organ changes associated with aging is severe enough to cause the disease, but all of them together increase the susceptibility to pathologies even in healthy elderly subjects. ${ }^{4}$

\section{Aging and thymus gland}

Thymus is the primary cell donor for the lymphatic system, like the bone marrow which is the cell donor for the hemopoietic system. It manufactures the immunocompetent $\mathrm{T}$ cells. Within the thymus the progenitor cells are created, then maturated and differentiated into mature $\mathrm{T}$ cells. The thymus gland is one of the contents of the anterior mediastinum as it lies behind the sternum but in front of the pericardium and heart. It is formed of two identical lobes; each lobe has a central medulla and a peripheral cortex. It develops from the third endodermal pharyngeal (branchial) pouch. The thymus is the largest and most active in neonates and pre-adolescents, afterwards it gradually involutes and ultimately disappears to be replaced by fat in elderly when it weighs $5 \mathrm{~g} .{ }^{5}$ It is not confirmed that adult thymus can produce significant numbers of new T cells. In congenital absence of thymus (DiGeorge Syndrome) there is deficiency of T cell immunity. ${ }^{6}$
Thymic involution refers to the process of multiple sessions of agerelated atrophy and redevelopment before the incidence of complete thymic degeneration. During involution, there is disruption of the thymic epithelial/endothelial ratio with progressive loss of pro-T cells. ${ }^{7}$ The mechanisms of thymic involution are still not fully understood. ${ }^{8}$ It was found that thymus gland in man was properly functioning till the age of sixties. ${ }^{9}$ Involution of the thymus is described as "programmed aging". Several authors relate the early involution of the thymus to an innate aging program while others attribute its incidence in early puberty to a developmental program that decelerates the growth rate. ${ }^{10}$ Photobiomodulation (PBM) (or low-level laser therapy, LLLT) is newly implemented to reduce thymic involution, improve immunity, and extend lifespan. ${ }^{11}$ In aging mice, there were disorganization of the thymic compartments, morphological alterations in the epithelial cells and their staining patterns, and increased apoptosis. ${ }^{12}$ Age-related thymic atrophy primarily affects its stromal cells. ${ }^{13}$

Changes in thymus weight with age and during pregnancy were investigated in mice. ${ }^{14}$ Thymus weight increased after birth, reached a maximum of $107.5 \mathrm{mg}$ at the age of 40 days, then decreased to become $48.9 \mathrm{mg}$ at the age of 100 days. In female mice thymus weight was markedly reduced by pregnancy and involution started 50 days after birth. MicroRNAs (miRNAs) may be considered as potential biomarkers for the study of sex- and age-related differences in involution of the thymus. ${ }^{15}$ In albino rats, of both sexes, no significant sex-differences were observed in fibronectin immunolocalization and in the histology of the thymus. In these animals, there were agerelated increases in the fibronectin content in the thymic capsule, the interlobular connective tissue, the perivascular tissue, and in the medulla and cortex. The lobular medulla/cortex ratio displayed age-dependent increases in rats of both sexes and the relative thymus weight was decreased. ${ }^{16}$ Using light microscopy, the quantity and sizes of Hassall's corpuscles in different periods of age were observed to depend on the vital form, shape and age of animal and human. ${ }^{17}$ In an immunohistochemical study, expression of matrix metalloproteinases 2 and 9 was decreased in thymus of old aged people when compared to middle aged people, this points out to the importance of these metalloproteinases in extracellular interaction and proliferation activity of aging thymus. ${ }^{18}$ Also, expression of these matrix metalloproteinase in thymus and pineal gland demonstrated a 
similar mechanism of remodeling extracellular matrix in both glands at aging. ${ }^{19}$

Properly functioning thymus is the needed for reduction of morbidity and mortality rates in infections and transplantations. ${ }^{20}$ Experimentally, zinc supplementation and sex steroid ablation are among the therapies to reduce thymic atrophy and boost thymus T cell output. ${ }^{21}$ Surgical manipulations, hormonal therapy, genetic procedures, as well as conventional and mitochondria-targeted antioxidants are reported as alternatives for reversal/arrest of programmed aging in thymic atrophy. ${ }^{22}$ In aging rats, experimental castration partially restored thymic structure, and long term administration of luteinizing hormonereleasing hormone agonist (LHRH-A) had led to proper organization of the thymic compartments and an obvious increase in the width of the cortex and its lymphocyte content. ${ }^{23} \mathrm{~A}$ significant increase in thymic cellularity and $\mathrm{T}$ cell numbers was noticed in offspring of mice and dams fed on a postnatal low-protein (PLP) diet. This led to the conclusion that maternal protein restriction during lactation slows aging of the immune system and prolongs the life span. ${ }^{24}$ The thymus and pineal glands run parallel involution. The two glands form a functional complementary unit that maintains the immune and endocrine systems during aging. ${ }^{25}$ Neonatal removal of the pineal gland leads to complete degeneration of the thymus, derangement of the immune system, and a wasting disease. The pineal gland is supposed to be responsible for involution of the thymus and control of its lifespan- determining function. ${ }^{26}$ Administration of thyrotropinreleasing hormone (TRH) or melatonin had corrected the rapid thymic involution induced by a lesion of the anterior hypothalamic region in mice. ${ }^{27}$ In elderly patients suffering from cardiomyopathy, fat specimens obtained from degenerated thymus (thymus adipose tissue, TAT) were more useful, than subcutaneous adipose tissue (SAT), as a source of vascular and endothelial factors. ${ }^{28}$

Adult mice injected with embryonic thymic calf extracts (ETCE), there was a fall in the level of cerebral and splenic unsaturated fatty acid peroxides. Histologically, thymus, liver and spleen of these injected animals resembled those of neonatal mice. In individuals treated with ETCE, presbyopia and climacteric symptoms disappeared. ${ }^{29}$ Immunological aspects have been frequently assessed in individuals who were early thymectomized during a childhood surgery for congenital heart anomalies. ${ }^{30}$ Aging and adult thymectomy have decreased the serum level of a circulating thymic factor (FTS) in mice. Thymuses, obtained from old mice and grafted into thymectomized young adult mice, could partially restore the circulating FTS level. On the other hand, newborn thymuses could not sufficiently restore the serum FTS level when grafted in old thymectomized mice. ${ }^{31}$ Thymus calf extract treatment and neonatal thymus graft have similar corrective effects on age-related changes in mice. Whether age-associated cataract in dogs could be cured or not, using thymus calf extract, remains a question for further studies. ${ }^{32}$ In cell-free extracts of mice thymus, there was no significant change in the activity of the proteolytic enzymes during thymus involution or during aging of the mice. On the contrary, the rate of protein synthesis diminished rapidly during involution, and continued to decrease at a slower rate during aging. ${ }^{33}$ In normal duck thymus during embryonic and post-embryonic periods, the apoptotic cells increased in number while the number of the proliferation cell nuclear antigen (PCNA)positive cells was significantly decreased with age. ${ }^{34}$ Experimentally, atopic autotransplantation of thymus tissue subjected to long-term cryoconservation was observed to slow down the rate of irreversible age-related atrophy of the thymus gland. ${ }^{35}$

The thymus is thought to be indulged in the pathogenesis of myasthenia gravis (MG) in patients with anti-acetylcholine receptor autoantibodies. A big percentage of MG patients are of three clinical categories: thymoma, early-onset MG (EOMG) below age of 40, lateonset MG (LOMG) above age of 40 . Thymectomy is widely used as a treatment of EOMG. ${ }^{36}$

\section{Aging and immune system}

Dysregulation of T-cell function plays an essential role in agerelated decline of the immune system. Since T-lymphocytes mature during their journey through the thymus, and this gland shows an age-related atrophy, thymic regression has been considered as the triggering event of this immune deterioration in elderly people. ${ }^{37}$ Thymic involution or 'thymic menopause' is thought to be the cause of aging of the immune system where there is diminution of the thymic epithelium, decrease of $\mathrm{T}$ cell output, and impaired cellmediated immunity. ${ }^{38}$ Premature aging of the immune system and incidence of cytomegalovirus (CMV) infection were sequelae of thymectomy during infancy ${ }^{39}$ In reduced or absent thymic function and aged immune system, the peripheral $\mathrm{T}$ cell population becomes regulated through the persistence and expansion of the $\mathrm{T}$ cell receptors together with their increased functional greediness for own peptides. ${ }^{40}$

Progressive decline in immunity with aging results in increased incidence of infections and impaired responses to vaccines. ${ }^{41}$ With the sixth decade of life, the human immune system begins profound aging-related changes which ultimately ends in a state of immunosenescence. The aging immune system becomes unable to protect against infections and cancer, to allow proper wound healing, and to respond typically to vaccination. Immune system aging accelerates other age-related pathologies, as in patients with the autoimmune syndrome of rheumatoid arthritis (RA). ${ }^{42}$ Systemic sclerosis ( $\mathrm{SSc}$ ) is an autoimmune disease manifested with fibrosis of multiple organs. Although it is not a disease of aging, the features of its associated fibrosis resemble those of aging-related fibrotic diseases. ${ }^{43}$ Two vasoactive hormones: serotonin and endothelin-1 are processed by the human thymus and they have the function of activation of T-lymphocyte. The level of expression of these hormones is high in aging and this could be used as an immunohistochemical assessment of their regulatory role in aging immunity. ${ }^{44}$ The prevalence of cancer, in man and animals, also increases with age. Aging paves the way for carcinogenesis through alterations in the immune and endocrine systems..$^{45,46}$

\section{Conclusion}

Thymic involution with age negatively impacts the immune system. Adequately functioning thymus gland and intact immune system are needed to protect against infections, autoimmune disorders, improper response to vaccination, rejection of transplants, and carcinogenesis.

\section{Acknowledgements}

None.

\section{Conflict of interest}

The author declares no conflict of interest. 


\section{References}

1. Desai KM, Chang $\mathrm{T}$, Wang $\mathrm{H}$, et al. Oxidative stress and aging: is methylglyoxal the hidden enemy? Can J Physiol Pharmacol. 2010;88(3):273-284.

2. Romano AD, Serviddio G, de Matthaeis A, et al. Oxidative stress and aging. J Nephrol. 2010;23 Suppl 15:S29-36.

3. Singh KK. Mitochondria damage checkpoint, aging, and cancer. Ann N Y Acad Sci. 2006;1067:182-190.

4. Wieczorowska-Tobis K. Organ alterations due to aging. Pol Arch Med Wewn. 2008;118 Suppl:63-69.

5. Zdrojewicz Z, Pachura E, Pachura P. The thymus: a forgotten, but very important organ. Adv Clin Exp Med. 2016;25(2):369-375.

6. Haynes BF, Sempowski GD, Wells AF, et al. The human thymus during aging. Immunol Res. 2000;22(2-3):253-261.

7. Franckaert D, Schlenner SM, Heirman N, et al. Premature thymic involution is independent of structural plasticity of the thymic stroma. Eur J Immunol. 2015;45(5):1535-1547.

8. Rezzani R, Nardo L, Favero G, et al. Thymus and aging: morphological, radiological, and functional overview. Age (Dordr). 2014;36(1):313351

9. Haynes BF, Markert ML, Sempowski GD, et al. The role of the thymus in immune reconstitution in aging, bone marrow transplantation, and HIV-1 infection. Annu Rev Immunol. 2000;18:529-560.

10. Khalyavkin AV, Krut'ko VN. Early thymus involution--manifestation of an aging program or a program of development? Biochemistry (Mosc). 2015;80(12):1622-1625.

11. Odinokov D, Hamblin MR. Aging of lymphoid organs: Can photobiomodulation reverse age-associated thymic involution via stimulation of extrapineal melatonin synthesis and bone marrow stem cells? J Biophotonics. 2017.

12. Aw D, Silva AB, Maddick M, et al. Architectural changes in the thymus of aging mice. Aging Cell. 2008;7(2):158-167.

13. Cepeda S, Griffith AV. Thymic stromal cells: Roles in atrophy and ageassociated dysfunction of the thymus. Exp Gerontol. 2018;105:113-117.

14. Endo T, Kanayama K. Changes in the weight of the thymus after birth and in pregnancy in mice. Res Commun Mol Pathol Pharmacol. 1998;101(3):307-310

15. Guo D, Ye Y, Qi J, et al. Age and sex differences in microRNAs expression during the process of thymus aging. Acta Biochim Biophys Sin (Shanghai). 2017;49(5):409-419.

16. Elcüman EA, Akay MT. Age-dependent immunolocalization of fibronectin and histological changes in the thymus of rats. Vet Res Commun. 1998;22(8):525-532.

17. Yurchinskij VJ. The morphological changes of Hassall corpuscles of the different maturity in vertebrate animals and human in different stages of age. Adv Gerontol. 2015;28(4):687-693.

18. Lin'kova NS, Poliakova VO, Kvetnol IM. The role of matrix metalloproteinases in human thymus aging. Adv Gerontol. 2011;24(2):216-219.

19. Lin'kova NS, Poliakova VO, Kvetnoı̆ IM. Single mechanism of remodelling extracellular matrix in thymus and pineal gland at aging. Adv Gerontol. 2011;24(3):420-422.

20. Lynch HE, Goldberg GL, Chidgey A, et al. Thymic involution and immune reconstitution. Trends Immunol. 2009;30(7):366-373.
21. Majumdar S, Nandi D. Thymic atrophy: experimental studies and therapeutic interventions. Scand J Immunol. 2008;87(1):4-14.

22. Shilovsky GA, Feniouk BA, Skulachev VP. Thymic involution in ontogenesis: role in aging program. Biochemistry (Mosc). 2015;80(12):1629-1631.

23. Marchetti B, Guarcello V, Morale MC, et al. Luteinizing hormonereleasing hormone (LHRH) agonist restoration of age-associated decline of thymus weight, thymic LHRH receptors, and thymocyte proliferative capacity. Endocrinology. 1989;125(2):1037-1045.

24. Heppolette CA, Chen JH, Carr SK, et al. The effects of aging and maternal protein restriction during lactation on thymic involution and peripheral immunosenescence in adult mice. Oncotarget. 2016;7(6):6398-6409.

25. Polyakova VO, Linkova NS, Kvetnoy IM, et al. Functional unity of the thymus and pineal gland and study of the mechanisms of aging. Bull Exp Biol Med. 2011;151(5):627-630.

26. Csaba G. The role of the pineal-thymus system in the regulation of autoimmunity, aging and lifespan. Orv Hetil. 2016;157(27):1065-1070.

27. Lesnikov VA, Korneva EA, Dall'ara A, et al. The involvement of pineal gland and melatonin in immunity and aging: II. Thyrotropin-releasing hormone and melatonin forestall involution and promote reconstitution of the thymus in anterior hypothalamic area (AHA)-lesioned mice. Int J Neurosci. 1992;62(1-2):141-153.

28. Coín Aragüez L, Murri M, Oliva Olivera W, et al. Thymus fat as an attractive source of angiogenic factors in elderly subjects with myocardial ischemia. Age (Dordr). 2013;35(4):1263-1275.

29. Czaplicki J, Błońska B. Do active substances of the thymus influence the processes of aging? I. Effects of treatment with embryonal and early fetal thymic calf extracts (ETCE) on some organs of grown-up young mice. Acta Med Pol. 1989;30(1-2):59-75.

30. Appay V. Sauce D, Prelog M. The role of the thymus in immunosenescence: lessons from the study of thymectomized individuals. Aging (Albany NY). 2010;2(2):78-81.

31. Bach MA, Beaurain G. Respective influence of extrinsic and intrinsic factors on the age-related decrease of thymic secretion. J Immunol. 1979;122(6):2505-2507.

32. Basso A, Rossolini G, Piantanelli A, et al. Aging reversibility: from thymus graft to vegetable extract treatment- application to cure an ageassociated pathology. Biogerontology. 2005;6(4):245-253.

33. Azelis AE, McMullen KM, Webster GC. Progressive reduction in protein synthesis during involution and aging of the mouse thymus. Mech Ageing Dev. 1982;20(4):361-368.

34. Fang J, Cui H, Peng X, et al. Developmental changes in cell proliferation and apoptosis in the normal duck thymus. Anat Histol Embryol. 2011;40(6):457-465

35. Kulikov AV, Arkhipova LV, Smirnova GN, et al. Slowing down the rate of irreversible age-related atrophy of the thymus gland by atopic autotransplantation of its tissue, subjected to long-term cryoconservation. Adv Gerontol. 2010;23(1):76-80.

36. Ströbel P, Moritz R, Leite MI, et al. The ageing and myasthenic thymus: a morphometric study validating a standard procedure in the histological workup of thymic specimens. J Neuroimmunol. 2008;201-202:64-73.

37. Ferrando-Martínez S, de la Fuente M, Guerrero JM, et al. Impact of thymic function in age-related immune deterioration. Rev Esp Geriatr Gerontol. 2013;48(5):232-237.

38. Taub DD, Longo DL. Insights into thymic aging and regeneration. Immunol Rev. 2005;205:72-93. 
39. Gress RE, Deeks SG. Reduced thymus activity and infection prematurely age the immune system. J Clin Invest. 2009;119(10):2884-2887.

40. Tatari-Calderone Z, Stojakovic M, Dewan R, et al. Age-related accumulation of $\mathrm{T}$ cells with markers of relatively stronger autoreactivity leads to functional erosion of T cells. BMC Immunol. 2012;13:8.

41. Schulz AR, Mälzer JN, Domingo C, et al. Low thymic activity and dendritic cell numbers are associated with the immune response to primary viral infection in elderly humans. J Immunol. 2015;195(10):4699-4711.

42. Weyand CM, Goronzy JJ. Aging of the immune system, mechanisms and therapeutic targets. Ann Am Thorac Soc. 2016;13(Suppl 5):S422-428.
43. Luckhardt TR, Thannickal VJ. Systemic sclerosis-associated fibrosis: an accelerated aging phenotype? Curr Opin Rheumatol. 2015;27(6):571576.

44. Poliakova VO. Serotonin and endotelin-1 expression in human thymus in aging. Adv Gerontol. 2007;20(1):47-51.

45. Anisimov VN. The relationship between aging and carcinogenesis: a critical appraisal. Crit Rev Oncol Hematol. 2003;45(3):277-304.

46. Anisimov VN, Sikora E, Pawelec G. Relationships between cancer and aging: a multilevel approach. Biogerontology. 2009;10(4):323-338. 